Research Article

\title{
Comparative evaluation of efficacy and safety of carboxymethylcellulose either alone or in combination with non-steroidal anti-inflammatory drug in the treatment of dry eye in a tertiary care teaching hospital
}

\author{
Saubhagya Sindhu', Shakti B. Dutta ${ }^{1}$, Mirza A. Beg ${ }^{1 *}$, Sanjeev K. Mittal' ${ }^{2}$, Sushobhan D. Gupta ${ }^{2}$
}

\begin{abstract}
${ }^{1}$ Department of Pharmacology, Shri Guru Ram Rai Institute of Medical \& Health Sciences, Dehradun, Uttarakhand, India, ${ }^{2}$ Department of Ophthalmology, Shri Guru Ram Rai Institute of Medical \& Health Sciences, Dehradun, Uttarakhand, India
\end{abstract}

Received: 08 January 2015

Revised: 20 January 2015

Accepted: 18 February 2015

\section{*Correspondence to:}

Dr. Mirza A. Beg, Email: mabeg1997@gmail.com

\section{Copyright: (C) the author(s), publisher and licensee Medip Academy. This is an open- access article distributed under the terms of the Creative Commons Attribution Non- Commercial License, which permits unrestricted non- commercial use, distribution, and reproduction in any medium, provided the original work is properly cited.}

\begin{abstract}
Background: Dry eye produces discomfort and reduced vision. The treatment of dry eyes has traditionally involved hydrating and lubricating artificial tears. The newer medications include non-steroidal anti-inflammatory drugs (NSAIDs) for the treatment of dry eye disorders. This study was designed to compare the effect of topical carboxymethylcellulose (CMC) alone or in combination with topical NSAID for the treatment of dry eye in a tertiary care teaching hospital.

Methods: A total of 60 patients diagnosed with dry eye were enrolled for a study period of 1 year. Patient of either sex (male/female), age between 18 and 70 years, and all diagnosed cases of dry eye in ophthalmology outpatient department were selected. Patients $(n=60)$ were stabilized on $\mathrm{CMC}$ for 2 weeks and thereafter divided into two groups. Group I ( $\mathrm{n}=30)$ received only topical CMC; Group II $(\mathrm{n}=30)$ received CMC+NSAID. The patients were followed up to 12 weeks. Diagnostic tests included Schirmer's test and tear break up time (TBUT). Ocular Surface Disease Index (OSDI) was used for assessing the Quality of Life. Analysis was done using GraphPad InStat software. $\mathrm{p}<0.05$ was considered significant.

Results: This was an open-label study revealing a mean age of $46.0 \pm 1.79$ years. Females $(56.67 \%)$ showed a significantly higher prevalence of dry eye symptoms compared to males $(43.33 \%)$. The mean duration of illness was $1.95 \pm 0.16$ years. Schirmer's test, TBUT test values and OSDI score in Group I and Group II at 0 and 12 weeks revealed significant intragroup difference $(p<0.0001)$. At 12 weeks intergroup comparison in Schirmer's test value $(p>0.05)$ and TBUT test value $(p>0.05)$ showed no significant difference while OSDI score revealed significant difference $(\mathrm{p}<0.05$ ). Burning, stinging, blurring of vision, photophobia, and hyperemia were among the common adverse effects seen.

Conclusion: Both groups showed significant improvement in Schirmer's test and TBUT test value and OSDI score at the end of the study. Intergroup comparison showed a significant difference with reference to OSDI score. Patients receiving NSAID reported more adverse effects.
\end{abstract}

Keywords: Dry eye, Carboxymethylcellulose, Non-steroidal anti-inflammatory drugs

\section{INTRODUCTION}

Dry eye is a multifactorial disease of the ocular surface and tear film which results in ocular discomfort, visual disturbances, and tear instability with potential damage to the cornea and conjunctiva. It has been defined by The National Eye Institute/Industry Workshop on Clinical Trials in dry eyes as "a disorder of the tear film due to tear deficiency or excessive tear evaporation, which causes damage to the interpalpebral ocular surface and is associated with symptoms of ocular discomfort." The overall prevalence of dry eye syndrome is estimated to be $5-35 \%$ in various population and the symptoms increase with age. ${ }^{2}$ The treatment of dry eyes has traditionally involved hydrating and lubricating the ocular surface which include usage of artificial tear drops (carboxymethylcellulose [CMC]). ${ }^{2,3}$ As inflammation is a key component in the pathogenesis of dry eye, non-steroidal anti-inflammatory drugs (NSAIDs) have recently been evaluated in dry eye clinical trials and in animal models. ${ }^{4,5}$ Dry eye disorder results in a diminished quality of life for those affected. In a study, it was found that patients with dry eye were significantly more likely to report 
difficulty with daily tasks than those without dry eye. ${ }^{6}$ The Ocular Surface Disease Index (OSDI) is a validated tool for measuring the subjective severity of dry eye. ${ }^{7}$ As dry eye is the most frequent disorder in ophthalmology practice, this study was designed to compare the effect of topical CMC alone or in combination with topical NSAID for the treatment of dry eye in a tertiary care teaching hospital at Dehradun, Uttarakhand.

\section{METHODS}

This study was conducted by the Department of Pharmacology in Ophthalmology Outpatient Department (OPD) at Shri Guru Ram Rai Institute of Medical and Health Sciences, Dehradun for a period of 1 year (January 2013-December 2013). A total of 60 dry eye patients were included in the study. Prior to the commencement of the study, approval was taken from Institutional Ethics Committee and written informed consent was obtained from all the participants.

\section{Study design}

This was an open-label study done in dry eye patients attending the ophthalmology OPD from January 2013 to December 2013. A total of 60 consecutive patients suffering from dry eye were included in the study. Patient selection criteria included patients of either sex (male/female), age between 18 and 70 years and diagnosed cases of dry eye. Exclusion criteria were any previous ophthalmology surgery or any uncontrolled systemic disease affecting eye. The patients were given drugs on the basis of physician's discretion, depending upon the condition of the patient at the time of presentation. A detailed history was taken for each patient and a thorough clinical examination was done in each case. Patients were stabilized initially for a period of 2 weeks with topical CMC and then subsequently divided into two groups on the basis of response to CMC. Group I $(n=30)$ CMC $(0.5 \%)$ eye drop TDS (one drop in each eye 3 times a day). Group II ( $\mathrm{n}=30) \mathrm{CMC}(0.5 \%)$ eye drop TDS+Ketorolac $(0.5 \%)$ eye drop TDS or Bromfenac $(0.09 \%)$ eye drop TDS (one drop in each eye 3 times a day). After stabilization, patients were followed up at 6 and 12 weeks. The parameters assessed in the present study included Schirmer's test, tear break up time (TBUT) test and OSDI. The Schirmer's test and TBUT test were done at 0,2, 6, and 12 weeks. The OSDI score was evaluated at 0,2 , and 12 weeks. The Schirmer's test was done by measuring the amount of wetting of Whatman 41 filter paper, $5 \mathrm{~mm}$ wide and $35 \mathrm{~mm}$ long. The result was expressed as millimeters of wetting from the fold at $5 \mathrm{mins}$. Wetting $<5 \mathrm{~mm}$ was suggestive of severe dry eye; $5-10 \mathrm{~mm}$ being moderate and $10-15 \mathrm{~mm}$ mild dry eye. For measuring TBUT, an impregnated fluorescein strip moistened with nonpreserved saline was instilled in the lower fornix of the eye of the patient. The patient was asked to blink several times. The unit of measurement was in seconds. A TBUT of $<5 \mathrm{sec}$ was suggestive of severe dry eye; $5-10 \mathrm{sec}$ being moderate and $10-15$ sec mild dry eye. OSDI is a 12-question survey tied to common symptoms that have an impact on qualityof-life. ${ }^{7}$ Answers are scored on a 5-point scale from "none of the time" (0) to "all of the time" (4). Typical questions include gauging how often a respondent's eyes have been sensitive to light or felt gritty in the previous week, whether or not the respondent has had difficulty reading or driving as a result of issues with his or her eyes, and whether or not the respondent felt any eye discomfort in windy or very dry environments. ${ }^{8}$ The patients were examined thoroughly at each follow-up visit and presence of any adverse event due to the drugs given was evaluated.

\section{Statistical analysis}

The treatment groups were compared and results were analyzed using unpaired and paired t-test in GraphPad InStat software. $\mathrm{p} \leq 0.05$ was considered to be significant.

\section{RESULTS}

A total of 60 patients were included in the study who had a mean age of $46.0 \pm 1.79$ years. Male:female ratio was $1: 1.31$. Mean duration of illness was $1.95 \pm 0.16$ years (Table 1 ). Baseline characteristics of all the patients enrolled for the study in reference to Schirmer's test, TBUT test and OSDI score were similar in the two groups as shown in the Table 1. Safety profile was assessed by noting the adverse events reported during the study. All results were expressed as mean \pm standard error of the mean.

The mean value of Schirmer's test at the start of the study was $7.7 \pm 0.70 \mathrm{~mm}$. The mean value of TBUT was $4.88 \pm 0.43$ sec. The mean value of OSDI score at the start of the study was $89.68 \pm 0.70$. At the end of 2 weeks, baseline Schirmer's test value in Group I was $8.17 \pm 0.78 \mathrm{~mm}(\mathrm{p}<0.005)$. In

Table 1: Baseline characteristics of the patients.

\begin{tabular}{|lc|}
\hline Parameters & Number (\%) \\
\hline Total number of patients (n) & 60 \\
\hline Mean age (years) & $46 \pm 1.79$ \\
\hline Male:female & $1.95 \pm 0.16$ \\
\hline $\begin{array}{l}\text { Mean duration of illness } \\
\text { (years) }\end{array}$ & \\
\hline Schirmer's & $7.8 \pm 0.81$ \\
\hline Group I & $7.6 \pm 0.6$ \\
\hline Group II & \\
\hline TBUT & $4.93 \pm 0.44$ \\
\hline Group I & $4.83 \pm 0.43$ \\
\hline Group II & \\
\hline OSDI & $87.64 \pm 1.41$ \\
\hline Group I & $90.22 \pm 1.05$ \\
\hline Group II & \\
\hline All & \\
\hline
\end{tabular}

All the values are expressed in mean \pm SEM. TBUT: Tear break up time, OSDI: Ocular Surface Disease Index, SEM: Standard error of the mean 
Group II, the schirmer's test value was $8.4 \pm 0.58 \mathrm{~mm}$ $(p<0.0001)$. At the end of 2 weeks, baseline TBUT values in Group I was $5.4 \pm 0.42 \mathrm{sec}(\mathrm{p}<0.0008)$. In Group II, the TBUT values were $5.4 \pm 0.36 \mathrm{sec}(\mathrm{p}<0.0003)$ (Table 2$)$. At the end of 2 weeks, baseline OSDI score in Group I was $82.97 \pm 1.67(p<0.0001)$. In Group II, the OSDI score was $83.34 \pm 1.36(p<0.0001)$ (Table 3$)$. Hence, the values had significantly improved at 2 weeks as compared to day 0 and the difference was highly significant. At the end of study period (12 weeks), intragroup comparison was done by using the values of Schirmer's test, TBUT and OSDI score. At 12 weeks Schirmer's test values in Group I were 15.4 \pm 0.62 $\mathrm{mm}(\mathrm{p}<0.0001)$. In Group II, the value was $16.5 \pm 0.48 \mathrm{~mm}$ $(\mathrm{p}<0.0001)$ (Figure 1). At 12 weeks TBUT test, values in Group I was $9.36 \pm 0.35 \mathrm{sec}(\mathrm{p}<0.0001)$. In Group II, the value was $10.2 \pm 0.23 \mathrm{sec}(\mathrm{p}<0.0001)$ (Figure 2). At 12 weeks OSDI score in Group I was 60.89 $\pm 1.99(\mathrm{p}<0.0001)$. In Group II, the OSDI score was $54.25 \pm 1.09(p<0.0001)$ (Figure 3). At the end of study period (12 weeks) intergroup comparison between the study groups was done for the Schirmer's, TBUT test values and OSDI score (Figure 4). Intergroup comparison of Schirmer's test and TBUT test values showed no significant difference ( $\mathrm{p}>0.05)$, but OSDI score showed significant difference at 12 weeks $(p<0.0001)$. Overall adverse events were reported in 22 patients out of 60 patients (Figure 5). 13 in Group I and 9 in Group II, the predominant side effects were burning and stinging sensation, followed by photophobia, blurring of vision and hyperemia. The side effects in both the groups were mild, transient, and did not necessitate stoppage of treatment.

\section{DISCUSSION}

Dry eye is a common complaint among middle-aged and older adults and its prevalence increases progressively with age. ${ }^{9-11}$ The average age of patients in the present study was $46 \pm 1.79$ years reflecting the usual age of disease manifestation. This was comparable to the previous studies where the age group of 41-50 years and 40-49 years showed a relative peak in the prevalence of dry eye symptoms. ${ }^{12,13}$ This peak reflects a dry eye state induced by environmental exposure, to which this age group, being the most active occupationally, is exceptionally prone. ${ }^{12}$ In our study, females $(56.67 \%)$ had significantly higher prevalence of dry eye symptoms compared to males $(43.33 \%)$. The male:female ratio in the present study was $1: 1.31$ which is comparable to previous studies..$^{11,12,14}$

Earlier studies have shown that CMC and NSAIDs are effective in the treatment of dry eye symptoms..$^{15-17}$ This

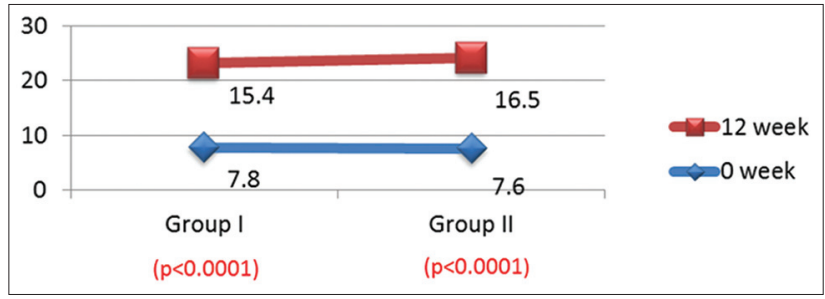

Figure 1: Comparison of Schirmer's test value at 0 weeks and 12 weeks.

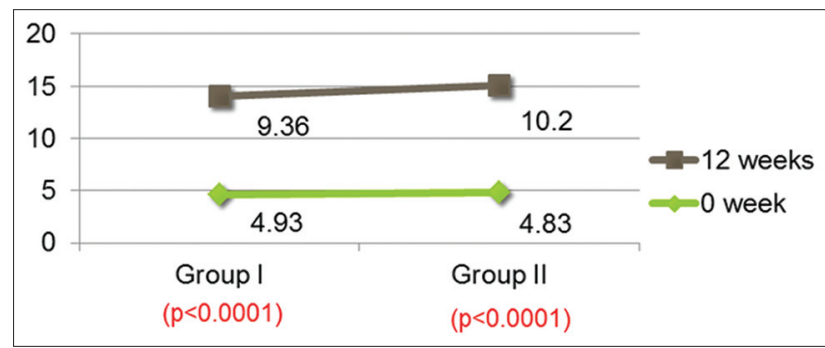

Figure 2: Comparison of tear break up time test value at 0 weeks and 12 weeks.

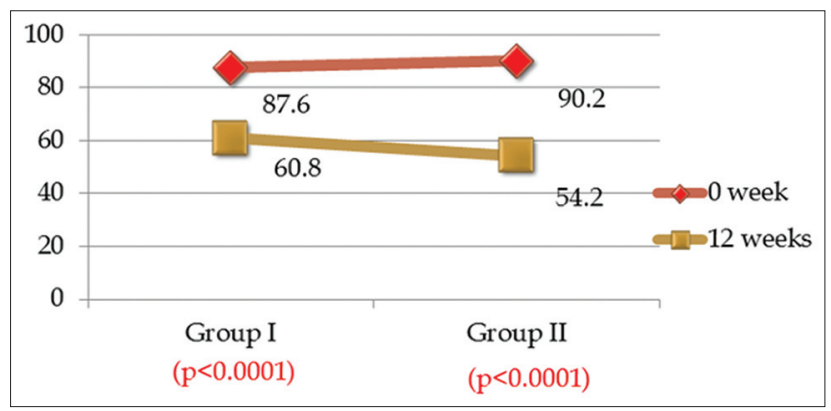

Figure 3: Comparison of ocular surface disease index score at 0 weeks and 12 weeks.

Table 2: Changes in Schirmer's and TBUT test values during the stabilization period (2 weeks).

\begin{tabular}{|c|c|c|c|c|c|c|}
\hline \multirow{2}{*}{$\begin{array}{l}\text { Groups } \\
(n=30)\end{array}$} & \multicolumn{2}{|c|}{ Schirmer's test (mm) } & \multirow[t]{2}{*}{ p-value } & \multicolumn{2}{|c|}{ TBUT test (sec) } & \multirow[t]{2}{*}{ p-value } \\
\hline & 0 weeks & 2 weeks & & 0 weeks & 2 weeks & \\
\hline I & $7.8 \pm 0.81$ & $8.17 \pm 0.78$ & $<0.005$ & $4.93 \pm 0.44$ & $5.4 \pm 0.42$ & $<0.0008$ \\
\hline II & $7.6 \pm 0.6$ & $8.4 \pm 0.58$ & $<0.0001$ & $4.83 \pm 0.43$ & $5.4 \pm 0.36$ & $<0.0003$ \\
\hline
\end{tabular}

All the values are expressed in mean \pm SEM. TBUT: Tear break up time, SEM: Standard error of the mean

Table 3: Progressive changes in OSDI score during the study period.

\begin{tabular}{|lcccccc|}
\hline Groups & 0 week & 2 weeks & p-value & 0 week & 12 weeks & p-value \\
\hline I & $87.64 \pm 1.41$ & $82.97 \pm 1.67$ & $<0.0001$ & $87.64 \pm 1.41$ & $60.89 \pm 1.99$ & $<0.0001$ \\
\hline II & $90.22 \pm 1.05$ & $83.34 \pm 1.36$ & $<0.0001$ & $90.22 \pm 1.05$ & $54.25 \pm 1.09$ & $<0.0001$ \\
\hline
\end{tabular}

All the values are expressed in mean \pm SEM. OSDI: Ocular Surface disease index, SEM: Standard error of the mean 


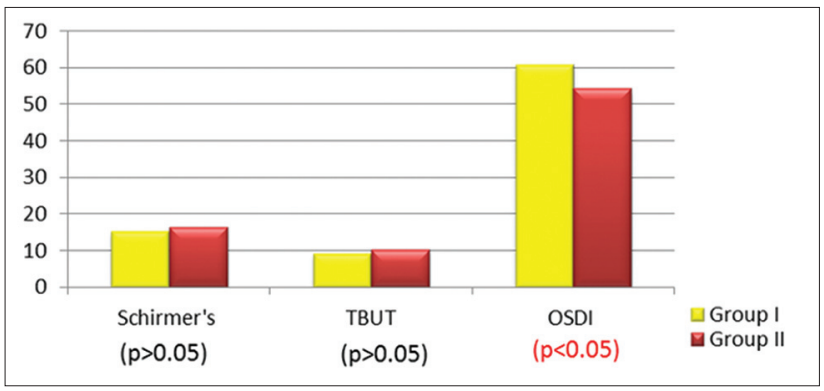

Figure 4: Intergroup comparison at the end of study period (12 weeks).

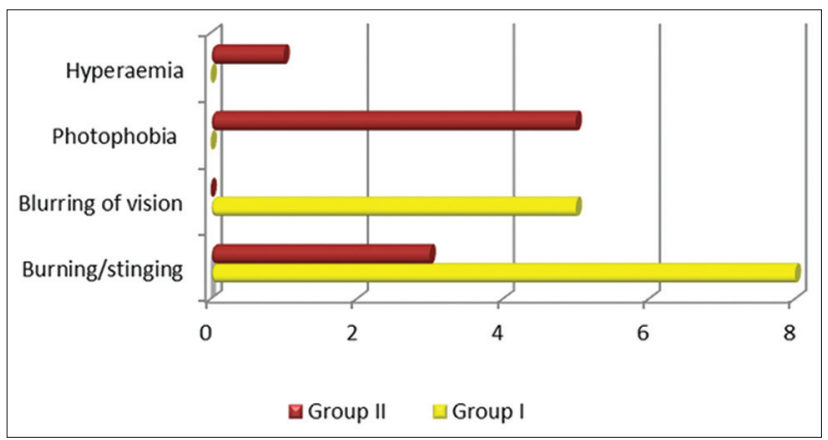

Figure 5: Adverse drug reactions during the study period.

finding was also substantiated in the present study with significant improvement in the Schirmer's test, TBUT test and OSDI questionnaire in both the study drug groups. The Schirmer's test values, TBUT values and OSDI score in each group continued to improve till the end of study period. This improvement in Schirmer's test and TBUT test values is comparable to previous studies. ${ }^{14,16,18,19}$ Improvement in OSDI score during the study period is comparable to previous studies. ${ }^{6,16,20}$ At 12 weeks, comparison was done between Group I and Group II. No intergroup difference was found between the groups with respect to Schirmer's and TBUT test, but significant difference was found in OSDI score between the two study groups, this is in accordance with previous study ${ }^{21}$ (Figure 4).

Few adverse effects were noted during the study period which were mild and did not require any alteration or discontinuation of study drugs. These adverse effects were comparable to those reported in previous clinical studies. ${ }^{14-18}$

\section{Study limitations}

This was an open-label study since both the doctor and the patient were aware of the medications being prescribed. Hence, there are more chances of errors. Second, a small sample size of only 60 patients was included in the study which may not be sufficient enough to demonstrate intergroup differences in evaluating the efficacy of study drugs. Third, the duration of patient follow-up was just up to 12 weeks. A longer follow-up period may have yielded different results. Hence, keeping these limitations in view, further studies with larger sample size and longer duration are required to evaluate the efficacy and safety of CMC and NSAIDs in the treatment of dry eye.

\section{CONCLUSION}

The patients who received $\mathrm{CMC}+\mathrm{NSAID}$ had a more significant improvement in Schirmer's, TBUT test values and OSDI score than the patients who received only CMC. However, no intergroup difference was found on comparing the Schirmer's and TBUT values at the end of study period. Significant intergroup difference was found in OSDI score on comparison at the end of study period.

Funding: No funding sources Conflict of interest: None declared

Ethical approval: The study was approved by the Institutional Ethics Committee

\section{REFERENCES}

1. Djalilian AR, Hamrah P, Pflugfeder SC. Dry eye. In: Krachmer JH, Mannis MJ, Holland EJ, editors. Cornea: Fundamentals, Diagnosis \& Management. $2^{\text {nd }}$ Edition. New York: Elsevier Mosby; 2005: 521-40.

2. Henderer JD, Rapuano JC. Ocular pharmacology. In: Bruton LL, Chabner BA, Knollmann BC, editors. Goodman \& Gilman's. The Pharmacological Basis of Therapeutics $12^{\text {th }}$ Edition. New York: McGraw Hill; 2011: 1773-801.

3. Meadows M. Dealing with Dry Eye. FDA Consumer Magazine. U.S. Food and Drug Administration; May-June, 2005.

4. Lekhanont K, Park CY, Smith JA, Combs JC, Preechawat P, Suwan-Apichon O, et al. Effects of topical anti-inflammatory agents in a botulinum toxin B-induced mouse model of keratoconjunctivitis sicca. J Ocul Pharmacol Ther. 2007;23(1):27-34.

5. El-Shazly AH, El-Gohary AA, El-Shazly LH, El-Hossary GG. Comparison between two cyclooxygenase inhibitors in an experimental dry eye model in albino rabbits. Acta Pharm. 2008;58(2):163-73.

6. Miljanovic B, Dana R, Sullivan DA, Schaumberg DA. Impact of dry eye syndrome on vision-related quality of life. Am J Ophthalmol. 2007;143(3):409-15.

7. Miller KL, Walt JG, Mink DR, Satram-Hoang S, Wilson SE, Perry HD, et al. Minimal clinically important difference for the ocular surface disease index. Arch Ophthalmol. 2010;128(1):94-101.

8. Ozcura F, Aydin S, Helvaci MR. Ocular surface disease index for the diagnosis of dry eye syndrome. Ocul Immunol Inflamm. 2007;15(5):389-93.

9. Schein OD, Muñoz B, Tielsch JM, Bandeen-Roche K, West S. Prevalence of dry eye among the elderly. Am J Ophthalmol. 1997;124(6):723-8.

10. McCarty CA, Bansal AK, Livingston PM, Stanislavsky YL, Taylor HR. The epidemiology of dry eye in Melbourne, Australia. Ophthalmology. 1998;105(6):1114-9.

11. Albietz JM. Prevalence of dry eye subtypes in clinical optometry practice. Optom Vis Sci. 2000;77(7):357-63.

12. Sahai A, Malik P. Dry eye: Prevalence and attributable risk 
factors in a hospital-based population. Indian J Ophthalmol. 2005;53(2):87-91.

13. Lee AJ, Lee J, Saw SM, Gazzard G, Koh D, Widjaja D, et al. Prevalence and risk factors associated with dry eye symptoms: A population based study in Indonesia. $\mathrm{Br} \mathrm{J}$ Ophthalmol. 2002;86(12):1347-51.

14. Kaercher T, Buchholz P, Kimmich F. Treatment of patients with keratoconjunctivitis sicca with Optive: Results of a multicenter, open-label observational study in Germany. Clin Ophthalmol. 2009;3:33-9.

15. Akingbehin AO. Comparative study of the intraocular pressure effects of fluorometholone $0.1 \%$ versus dexamethasone $0.1 \%$. Br J Ophthalmol. 1983;67(10):661-3.

16. Sindt CW, Foulks GN. Efficacy of an artificial tear emulsion in patients with dry eye associated with meibomian gland dysfunction. Clin Ophthalmol. 2013;7:1713-22.

17. Yanai K, Huang J, Kadonosono K, Uchio E. Corneal sensitivity after topical bromfenac sodium eye-drop instillation. Clin Ophthalmol. 2013;7:741-4.

18. Cohen S, Martin A, Sall K. Evaluation of clinical outcomes in patients with dry eye disease using lubricant eye drops containing polyethylene glycol or carboxymethylcellulose. Clin Ophthalmol. 2014;8:157-64.

19. Bragheeth MA, El-Kasaby MI. Topical corticosteroid drops in the management of dry eye. Egypt J Hosp Med. 2010;39:181-8.

20. Kim TH, Kang JW, Kim KH, Kang KW, Shin MS, Jung SY, et al. Acupuncture for the treatment of dry eye: a multicenter randomised controlled trial with active comparison intervention (artificial teardrops). PLoS One. 2012;7(5): 36638.

21. Schechter BA. Ketorolac during the induction phase of cyclosporin-A therapy. $\mathrm{J}$ Ocul Pharmacol Ther. 2006;22(2):150-4.

doi: 10.5455/2319-2003.ijbcp20150409

Cite this article as: Sindhu S, Dutta SB, Beg MA,

Mittal SK, Gupta SD. Comparative evaluation of efficacy and safety of carboxymethylcellulose either alone or in combination with non-steroidal anti-inflammatory drug in the treatment of dry eye in a tertiary care teaching hospital. Int $\mathrm{J}$ Basic Clin Pharmacol 2015;4:245-9. 